$82 \%)$ believed doctors should enquire about sexual matters, although only the minority $(2,9 \%)$ had been involved in such discussion with their doctor. Many responders $(14,64 \%)$ felt at ease with sexual discussion, yet, few $(5,23 \%)$ regarded their doctor as comfortable with this. Furthermore, women reported less comfort, but no less interest in sexual discourse than men $(P=0.03)$, suggesting particular understanding should be employed when taking sexual histories from older females. Increasing age $(P=$ 0.03 ) and cohabitation $(P=0.08)$, were found to be associated with a decreased desire to discuss sexual issues.

Aged sexuality is still a taboo. It is widely believed by doctors that sexual enquiry is inappropriate and often unnecessary among older adults, ${ }^{3}$ however, this study and American research ${ }^{4}$ indicate that this is not always the case. The implication being that physicians are not meeting the sexual healthcare needs of older mental health patients.

While we found reluctance among many older people to respond to the survey, of those who did, most older patients wished to be asked about sexual issues. However, clinicians need to do this sensitively. The lack of response, and number of complaints about the survey, highlights a crucial finding; while sexual enquiry is acceptable and welcomed in the US, it may not be so well tolerated in the UK.

In summary, many older age psychiatric patients want to talk about their sex lives with doctors but are currently not afforded the opportunity. GPs are well placed to assess issues of sexual dysfunction. Older, UK-based populations are difficult to survey regarding sex but this study indicates that further research would be valuable.

\section{James Warner}

Department of Psychiatry, Imperial College London, W2 1PD.

E-mail: j.warner@imperial.ac.uk

\section{Elizabeth Starren}

SHO in medicine, West Middlesex

University Hospital

elizabeth.starren00@imperial.ac.uk

\section{Gareth Walker}

F2 trainee in General Practice,
Ealing Hospital

Gareth.walker0o@imperial.ac.uk

\section{REFERENCES}

1. Masters W, Johnson V. Sex and the aging process. J Am Geriatr Soc 1981; 29(9): 385-390.

2. Matthias R, Lubben J, Atchison K, Schweitzer S. Sexual activity and satisfaction among very old adults: results from a community dwelling population survey. Gerontologist 1997; 37(1): 6-14.

3. Bouman W, Arcelus. Are psychiatrists guilty of 'ageism' when it comes to taking a sexual history? Int $J$ Geriatr Psychiatry 2001; 16(1): 27-31.

4. Bedell E, Duperval M, Goldberg R. Cardiologist's discussions about sexuality with patients with chronic coronary artery disease. Am Heart J 2002; 144(2): 239-242.

10.3399/bjgp08X277069

\section{Top tips}

Regarding 'Top Tips in 2 minutes', Ruth Bastable, et al, ${ }^{1}$ mentions 'you are asked to talk for an hour'. She will find the audience asleep. They can concentrate for 35 minutes with a maximum of 25 slides. Then questions for however long the organiser requires. That's when the audience wakes up again. She must have a good chairman. Speakers who extend their time are a menace and should be stopped.

\section{Ivor E Doney}

GP, Bristol.

\section{REFERENCE}

1. Bastable R, Rann S, Barker V. Top Tips in 2 minutes. $\mathrm{Br} J$ Gen Pract 2008; 58(546): 62

10.3399/bjgp08X277078

\section{Doctors' content}

The editorial ${ }^{1}$ discussing the Original Paper of the same issue, by Whalley, Sibbald and Gravelle ${ }^{2}$ states that there is 'contentment in general practice - for now'. While accurately reflecting the contents of the paper you fail to highlight that the latest survey was over 2 years ago. I would humbly suggest that a survey reported now would give markedly different and more negative responses. Management at the Department of Health and in PCTs though will no doubt find succour in your editorial.

I am concerned that the British Journal of General Practice should not have reflected the fast moving changes in attitude that are currently present in general practice and in failing to do so will lose credibility with our colleagues.

\section{Christopher Elliott \\ GP, Sutton, Surrey.}

E-mail: celliott@nhs.net

\section{REFERENCES}

1. O'Dowd T. Contentment in general practice - for now. Br J Gen Pract 2007; 50(546): 5-6.

2. Whalley D, Gravelle $H$ and Sibbald B. Effect of the new contract on GPs' working lives and perceptions of quality of care: a longitudinal study. Br J Gen Pract 2007; 50(546): $8-14$.

10.3399/bjgp08X277087

\section{Participating in media surveys}

I listened with weary resignation to BBC radio and television on $31 \mathrm{Dec} 2007$ that ran a story on urgent and non-urgent GP referral of women with lumps to breast clinics.

The item was based on a small survey of 200 GPs for Radio 4 which was carried out by the charity Breakthrough Breast Cancer. The story was headlined as 'Cancer referral confusing GPs'.

The survey recognised that most family doctors were following NICE guidelines. This fact, however, was lost in the media clamour which picked up on one aspect of the survey which was that about a third of GPs stated they would use judgement on whether to refer urgently a woman under 30 with a lump. This was seized on as a breech of guidelines and of course it grabbed all the (negative) headlines.

Making referral decisions using guidelines and clinical judgement, instead of simply following guidelines at all times, seems to be regarded as negligent by the media and pressure groups. Do they really think that in this case, it would be better to refer all women with a breast lump under the 2-week rule and overload the system?

The open season on GPs continues.

\section{Paul McGowan}

GP, Alma Medical Centre, Stockton-on-Tees. E-mail: paul.mcgowan@nhs.net.

10.3399/bjgp08X277096 